Check for updates

Cite this: Mater. Adv., 2021, 2, 7024

Received 13th July 2021

Accepted 9th September 2021

DOI: $10.1039 / \mathrm{d} 1 \mathrm{ma} 00605 \mathrm{c}$

rsc.li/materials-advances

\title{
Transition metal coordination frameworks as artificial nanozymes for dopamine detection via peroxidase-like activity $\dagger$
}

\author{
Muppidathi Marieeswaran and Perumal Panneerselvam (D) *
}

\begin{abstract}
Enzyme-like metal-organic frameworks are currently one type of star material in the fields of artificial enzymes and analytical sensing. However, there has been little progress in making use of MOF structures based on a catalytically active metal center. Herein, transition metal coordination frameworks (Cu-HMT and $\mathrm{Ni}-\mathrm{HMT}$ ) are used as artificial nanozymes for the visual detection of a Parkinson's disease biomarker (dopamine, DA) through peroxidase-like catalytic activity. We prepared hexamine and transition metal coordination frameworks ( $\mathrm{Cu}-\mathrm{HMT}$ and $\mathrm{Ni}-\mathrm{HMT}$ ) through a trouble-free green synthetic route and characterized them in detail. Comparative studies of peroxidase mimic activity were conducted in the presence of the as-prepared $\mathrm{Cu}-\mathrm{HMT}$ and Ni-HMT. Impressively, Cu-HMT possesses formidable peroxidase mimic activity, which allows UV-vis spectra and naked-eye detection of DA. Furthermore, Ni-HMT has its own limitations, including lower water stability and poorer activity compared to Cu-HMT. However, the peroxidase-like activity of Cu-HMT was strongly inhibited in the presence of DA. Notably, the proposed sensing system was proven to show an enhanced inhibition effect, including visual detection, high selectivity, specificity and low detection limits of 0.7 and $4.2 \mathrm{mM}$ for $\mathrm{H}_{2} \mathrm{O}_{2}$ and DA, respectively. Based on this phenomenon, the as-synthesized $\mathrm{Cu}-\mathrm{HMT}$ could be used as a kind of nanozyme to enhance the performance of colorimetric sensors.
\end{abstract}

\section{Introduction}

Nanozymes are a kind of substituent inspired by natural enzymes. They are widely used in many applications, including industrial, biomedical, catalysis and sensing applications. ${ }^{1}$ Indeed, they have inherent peroxidase-mimic, oxidase-mimic, catalyst-mimic, and superoxide-like activities. Among these, their peroxidase-mimic activity has attracted great attention due to its promising properties. ${ }^{2,3}$ Most nanozymes have mimic properties, but less activity compared to natural enzymes. Thus, it is necessary to improve the design and development of highly catalytic nanozymes to outperform natural enzymes. So far, various nanozymes have demonstrated to act as peroxidase nanozymes, including $\mathrm{Fe}_{3} \mathrm{O}_{4}, \mathrm{Mn}_{3} \mathrm{O}_{4}, \mathrm{Co}_{3} \mathrm{O}_{4}, \mathrm{Cu}_{2} \mathrm{O}$, $\mathrm{Ag}$ nanoparticles (NPs), Au NPs, Pt NPs, and carbon-based materials. ${ }^{4-8}$ Their nanozyme activity can be adjusted by various stimuli, such as $\mathrm{pH}$, temperature and steric hindrance. Many researchers have aimed to enhance the activity of nanozymes using external stimuli such as size, shape and surface charges and

Department of Chemistry, SRM Institute of Science and Technology, Kattankulathur, Chennai 603 203, Tamil Nadu, India. E-mail: panneerp1@srmist.edu.in, panneerchem82@gmail.com

$\dagger$ Electronic supplementary information (ESI) available. See DOI: 10.1039/d1ma00605c various modifications and compositions. ${ }^{9,10}$ Therefore, tremendous efforts have been dedicated to improving the catalytic activity of metal-organic frameworks (MOFs) as better candidates to replace nanomaterial-based nanozymes.

MOFs have been given more importance in the field of nanozymes due to their high surface area, numerous active sites, pore tunability, cost-effectiveness, etc. ${ }^{11,12}$ MOFs are promising materials for many applications, such as gas isolation, catalysis, energy storage or transfer, biomedical applications, drug delivery, sensors and environmental applications. ${ }^{13-16}$ Additionally, MOFs have formidable peroxide-like activity, and can oxidize $3,3^{\prime}, 5,5^{\prime}$ tetramethylbenzidine (TMB) in the presence of $\mathrm{H}_{2} \mathrm{O}_{2}$ via an electron transfer process. ${ }^{17,18}$ So far, most pristine MOFs and modified MOFs have exhibited pioneering peroxidase catalysis for the detection of $\mathrm{H}_{2} \mathrm{O}_{2}$, dopamine (DA), ascorbic acid, glucose, uric acid, poisonous metal ions and bioactive materials. ${ }^{19-26}$ Recently, a few reports have documented DA detection via peroxidase-like activity. Jang et al. reported the $\mathrm{Cu}(\mathrm{PDA})(\mathrm{DMF}) \mathrm{MOF}$ for the detection of $\mathrm{DA},{ }^{27}$ and a few hybrid materials also have excellent peroxidase-like activity. ${ }^{28-32}$ Zheng et al. presented MOF808, which was used to analyze ascorbic acid at neutral $\mathrm{pH} .{ }^{33}$ Most MOFs are synthesized using hydrothermal or solvothermal methods under harsh conditions in toxic solvents (DMF, acetic acid). ${ }^{34,35}$ As is known, hexamethylenetetramine (HMT)-based coordination frameworks have 
pioneering super-capacitor and battery applications after calcination. It is also interesting to note that the HMT-based frameworks are synthesized using an eco-friendly synthetic method (room temperature and aqueous medium) and serve as oxidase activity mimics.

DA acts as a neurotransmitter, which is one the essential nutrient for human bodies. Eventhough, the higher concentration can leads nervous infection and premature death. Disordered levels of DA can lead to dangerous diseases such as schizophrenia, Alzheimer's, Parkinson's and Huntington's diseases. $^{36,37}$ So far, fluorescence, electrochemical and colorimetric methods, and surface plasma resonance (SPR) have been developed for DA detection. ${ }^{38,39}$ However, the abovementioned techniques have limitations such as photoleaching, time-consuming operation, and inference from uric acid and ascorbic acid, which typically limits their selectivity. Therefore, developing new approaches with superior performance for DA detection is still necessary. Among them, visual and colorimetric methods have attracted great interest due to their simplicity and specificity and the fact that interestingly, the results can be analyzed by the naked eye without using any expensive instruments.

In this context, we developed transition-metal-containing coordination frameworks $\left(\mathrm{Cu}^{2+}\right.$ and $\left.\mathrm{Ni}^{2+}-\mathrm{HMT}\right)$ using a green synthetic one-pot method. They are constructed using HMT as a bridging ligand and $\mathrm{Cu}^{2+}$ and $\mathrm{Ni}^{2+}$ as metal nodes. Asprepared $\mathrm{Cu}^{2+}-\mathrm{HMT}$ and $\mathrm{Ni}^{2+}-\mathrm{HMT}$ showed superior peroxidase-mimic activity and were able to oxidize TMB with $\mathrm{H}_{2} \mathrm{O}_{2}$ to generate the product oxTMB. Moreover, $\mathrm{Cu}^{2+}-\mathrm{HMT}$ has higher inherent catalytic acidity compared to $\mathrm{CuO}$, NiO NPs and $\mathrm{Ni}^{2+}$-HMT due to the abundant reactive active species. However, DA inhibits the peroxidase-like activity of $\mathrm{Cu}-\mathrm{HMT}$. Based on this approach, i.e., the enhancement and inhibition of the oxidation of TMB, superior selectivity and sensitivity in the detection of $\mathrm{H}_{2} \mathrm{O}_{2}$ and DA are achieved via a colorimetric method. As shown in Scheme 1b, Cu-HMT oxidized TMB

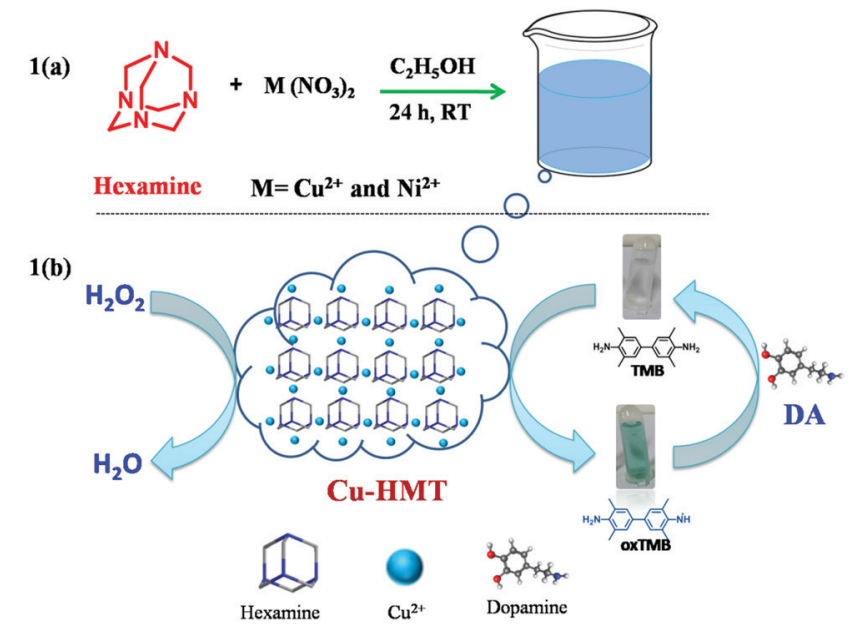

Scheme 1 Schematic illustration of the transition-metal-based hexamine coordination frameworks (a); mechanism of the peroxidase-based activity of $\mathrm{Cu}-\mathrm{HMT}$ for the detection of $\mathrm{H}_{2} \mathrm{O}_{2}$ and DA (b). via reactive active species from the decomposition of $\mathrm{H}_{2} \mathrm{O}_{2}$. Nevertheless, DA caused decreased oxidation of TMB due to its competitive consumption of the reactive oxygen species (ROS), which results in reduced peroxidase-mimic activity and a hypochromic effect in the absorption spectrum. Therefore, $\mathrm{H}_{2} \mathrm{O}_{2}$ and DA could be detected according to the colour change. Thus, we demonstrated that this facile methodology offers rapid, reliable and selective detection for an $\mathrm{H}_{2} \mathrm{O}_{2}$ and DA assay.

\section{Experimental section}

\subsection{Reagents and materials}

Copper nitrate $\left(\mathrm{Cu}\left(\mathrm{NO}_{3}\right)_{2}\right)$, nickel nitrate $\left(\mathrm{Ni}\left(\mathrm{NO}_{3}\right)_{2}\right.$, hexamine, $3,3^{\prime}, 5,5^{\prime}$-tetramethylbenzidine (TMB), ethanol, hydrogen peroxide $\left(\mathrm{H}_{2} \mathrm{O}_{2}\right)$, DA, glucose $(\mathrm{G})$, fructose $(\mathrm{Fr})$, cysteine $(\mathrm{Cy})$, uric acid (UA), ascorbic acid (AA), p-benzoquinone (PBQ), methanol $(\mathrm{MeOH})$, isopropyl alcohol (IPA) were all purchased from SRL chemicals as analytical grade reagents and used without further purification.

\subsection{Characterization}

The morphology and crystalline structure information were evaluated using scanning electron microscopy (SEM, FEI Quanta FEG 200) and high-resolution transmission electron microscopy (HRTEM, JEOL, JEM, Fb-2000). The X-ray diffraction patterns were obtained using a PAN analytical X'pert pro $\mathrm{X}$-ray diffractometer with $\mathrm{CuK} \alpha$ radiation. In the bonding information studies, an Agilent Technologies FT-IR spectrometer (USA) was used to record the Fourier-transform infrared (FT-IR) spectra in attenuated total reflectance (ATR) mode. Thermal stability was analysed via thermogravimetry analysis (STA 2500 Thermoanalyzer).

\subsection{Synthesis of transition-metal-based hexamine coordination frameworks $\left(\mathrm{Cu}^{2+}\right.$ and $\left.\mathrm{Ni}^{2+}-\mathrm{HMT}\right)$}

The transition-metal-based coordination frameworks $\left(\mathrm{Cu}^{2+}\right.$ HMT \& $\mathrm{Ni}^{2+}$-HMT) were synthesized via a previously reported procedure with minor modifications. ${ }^{40,41}$ Typically, $1 \mathrm{~g}$ ( $\left.1 \mathrm{~mm}\right)$ of hexamine was dissolved in $10 \mathrm{~mL}$ ethanol and stirred at ambient temperature. Subsequently, $0.7 \mathrm{~g}(1 \mathrm{~mm})$ of $\mathrm{Cu}\left(\mathrm{NO}_{3}\right)_{2}$ in $5 \mathrm{~mL}$ of ethanol was added drop-wise to the above solution. Immediately, the bluish-colored solution formed a blue-colored precipitate, and it was stirred for a further 24 hours. The slightly bluish precipitate was washed with ethanol several times and dried at $70{ }^{\circ} \mathrm{C}$ overnight. Finally, $\mathrm{Cu}-\mathrm{HMT}$ was collected. Ni-HMT was also synthesized using the above procedure. The slightly greenish Ni-HMT was collected.

\subsection{Peroxidase-like activity}

The reaction of the catalyst $\mathrm{Cu}-\mathrm{HMT}\left(0.6 \mathrm{mg} \mathrm{mL}^{-1}\right)$, TMB $(100 \mu \mathrm{l}$ of $10 \mathrm{mM})$ and $\mathrm{H}_{2} \mathrm{O}_{2}(100 \mu \mathrm{l}$ of $0.1 \mathrm{M})$ was carried out in acetate buffer solution $(\mathrm{pH} 4.5)$ under ambient conditions. During the reaction, the colorless TMB became blue-colored oxTMB, which was measured using UV-vis spectroscopy and the 
naked eye. Furthermore, different conditions were optimized, including the TMB concentration, catalyst loading, $\mathrm{pH}$, and concentration of $\mathrm{H}_{2} \mathrm{O}_{2}$.

\subsection{Real sample analysis}

We applied this colorimetric detection platform to determine DA in human urine. Urine was obtained from human subjects, and their consent was recorded through Sri Ramaswamy Memorial Hospital (SRM Hospital). Moreover, a recovery experiment was performed using the standard addition method, in which different concentrations of DA were spiked in human urine samples for analysis.

\section{Results and discussion}

\subsection{Characterization of the synthesized $\mathrm{Cu}-\mathrm{HMT}$}

The synthetic method gave the pure transition-metal-based hexamine coordination frameworks $\left(\mathrm{Cu}^{2+}-\mathrm{HMT} \& \mathrm{Ni}^{2+}-\mathrm{HMT}\right)$ in high crystalline yield, and is systematically illustrated in Scheme 1a. In terms of coordination chemistry, hexamethylenetetramine (HMT) is a convenient building block due to its

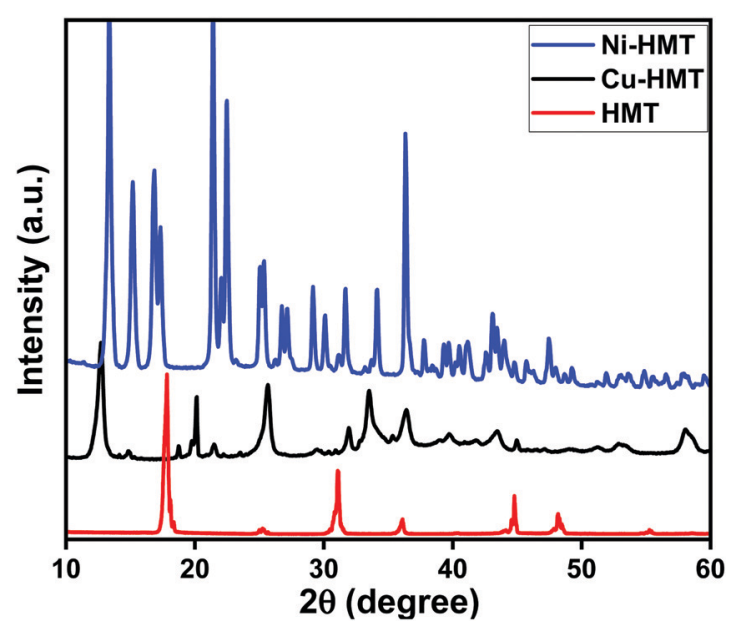

Fig. 1 PXRD patterns of hexamine, $\mathrm{Cu}-\mathrm{HMT}$ and $\mathrm{Ni}-\mathrm{HMT}$. diverse chelating ability. It can easily form stoichiometric molecular compounds with transition metals through different coordination sites. In the synthetic procedure, HMT was reacted with the inorganic metal nodes $\left(\mathrm{Cu}\left(\mathrm{NO}_{3}\right)_{2}\right.$ and $\left(\mathrm{Ni}\left(\mathrm{NO}_{3}\right)_{2}\right)$ to form the crystalline MOFs $\left.\left[\mathrm{Cu}-(\mathrm{HMT})_{2} \mathrm{NO}_{3}\right)_{2}\right]_{n}$ and $\left.\left[\mathrm{Ni}-(\mathrm{HMT})_{2} \mathrm{NO}_{3}\right)_{2}\right]_{n}$, based on previous literature. ${ }^{42}$ According to theory, the $\mathrm{Cu}$ and $\mathrm{Ni}$ were coordinated with the oxygen atoms of six water molecules to form an octahedral structure. The $\mathrm{Cu}$ cations bind with the HMT ligand via hydrogen bonds between the nitrogen of HMT and a water molecule to form a 1D Cu/HMT zigzag structure. The molecular formula of the 1D zigzag chain can be expressed as $\mathrm{Cu}\left(\mathrm{NO}_{3}\right)_{2}\left(\mu_{2}-\mathrm{HMT}\right)_{2} \cdot\left(\mathrm{H}_{2} \mathrm{O}\right)_{x}{ }^{43}$ These $1 \mathrm{D}$ zigzag chains can easily assemble into a $2 \mathrm{D}$ supramolecular framework. Finally, the 2D supramolecular framework assembles into microplates of $\mathrm{Cu}-\mathrm{HMT}$ MOFs. The assembly process is typically driven by strong hydrogen bonds because of the bond-accepting behavior of HMT. ${ }^{44}$ After ultrasonic exfoliation in ethanol solution, $\mathrm{Cu}-\mathrm{HMT}$ MOF nanosheets are obtained, which further verified that the microplates are stacked 2D coordination frameworks.

The as-synthesized Cu-HMT and Ni-HMT crystalline phases were extensively investigated using powder X-ray diffraction (PXRD). The PXRD spectra of the synthesized $\mathrm{Cu}-\mathrm{HMT}$ and $\mathrm{Ni}-\mathrm{HMT}$ were measured at room temperature over the $10-90^{\circ}$ range. As shown in Fig. 1a, the pristine hexamine exhibited strong characteristic diffraction peaks with a highly crystalline nature. The HMT coordinated with the inorganic nodes copper $\left(\mathrm{Cu}^{2+}\right)$ and nickel $\left(\mathrm{Ni}^{2+}\right)$, as shown in Fig. 1a and b. After the formation of the coordination framework, the HMT diffraction peaks were slightly shifted, which emphasizes that HMT coordinated with $\mathrm{Cu}^{2+}$ to form the copper-based hexamine coordination framework $(\mathrm{Cu}-\mathrm{HMT})$. Fig. $1 \mathrm{~b}$ shows the crystalline nature of the nickel-based hexamine coordination framework (Ni-HMT). These diffraction patterns matched well with earlier reports (ref. no. 719423 and 04-0850). ${ }^{40,45}$ The diffraction results confirmed the formation of $\mathrm{Cu}^{2+}$ - and $\mathrm{Ni}^{2+}$-based hexamine coordination frameworks (Cu-HMT and Ni-HMT).

The bonding interactions of the prepared $\mathrm{Cu}-\mathrm{HMT}$ and $\mathrm{Ni}-$ HMT were analyzed via FT-IR spectroscopy. Fig. $2 \mathrm{a}$ and $\mathrm{b}$ show

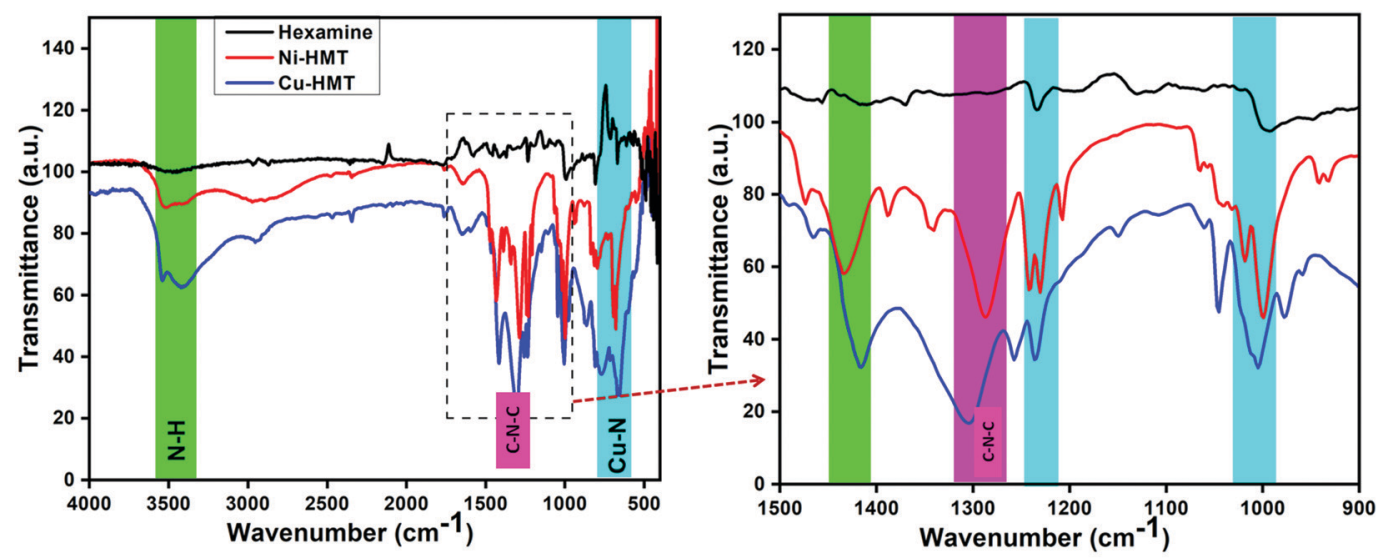

Fig. 2 FT-IR spectra of $\mathrm{Cu}-\mathrm{HMT}$ and $\mathrm{Ni}-\mathrm{HMT}$. 

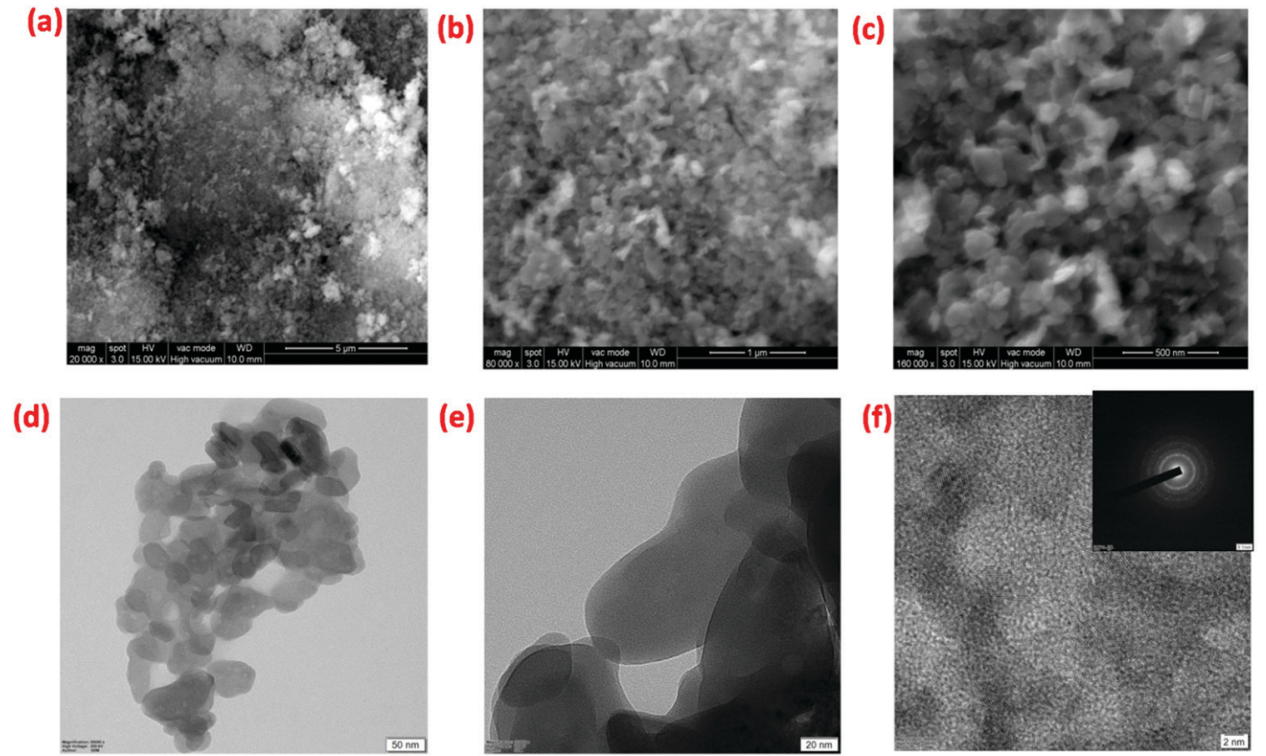

(g)
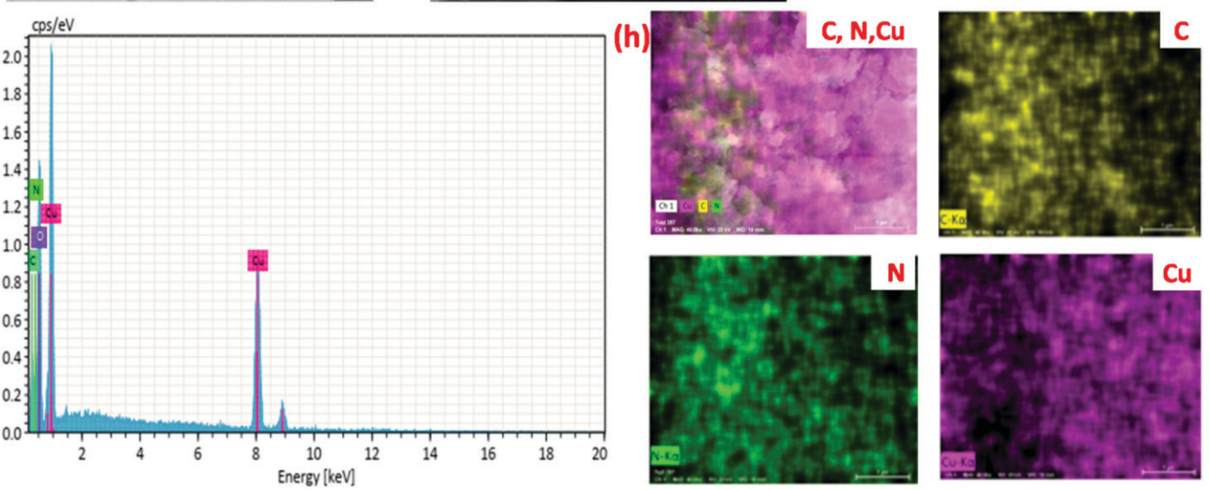

Fig. 3 Morphology study of the synthesized Cu-HMT. SEM images (a-c) and TEM images (d-f). SEM-EDX spectra (g) and elemental mapping of $\mathrm{Cu}-\mathrm{HMT}$ (h): carbon (yellow); nitrogen (green); copper (violet).

the bonding vibrations of HMT, Cu-HMT and Ni-HMT. The precursor HMT exhibited two major bands at 998 and $1234 \mathrm{~cm}^{-1}$, which were assigned as $\mathrm{C}-\mathrm{N}$ bands. Notably, in previous reports, it has been pointed out that hexamine (HMT) acts as a bidentate bridging ligand. ${ }^{42}$ When the inorganic node $\left(\mathrm{Cu}^{2+}\right)$ was coordinated with HMT, the HMT characteristic bands were split into doublets due to the coordination between the electron-density-rich nitrogen atom and $\mathrm{Cu}^{2+}$, which clearly indicates the formation of $\mathrm{Cu}-\mathrm{HMT}$. The $\mathrm{Cu}-\mathrm{N}$ vibration band appeared at $560 \mathrm{~cm}^{-1}$, and the stretching vibration peaks at $1620 \mathrm{~cm}^{-1}$ and $1428 \mathrm{~cm}^{-1}$ were ascribed to the deformation vibration of $-\mathrm{C}-\mathrm{N}$. Based on the vibration spectra, it can be concluded that $\mathrm{Cu}-\mathrm{N}-\mathrm{Cu}$ linkages were formed. Fig. $2 \mathrm{~b}$ presents an enlargement of a region of the spectra, showing that the HMT bands were split into doublets and the $\mathrm{M}-\mathrm{O}$ bands.

The morphology of the prepared $\mathrm{Cu}-$ and Ni-HMT samples were observed using SEM and TEM, as shown in Fig. 3 and Fig. S1 (ESI $\dagger$ ). Fig. 3a-c display the microplate morphology of the synthesized $\mathrm{Cu}-\mathrm{HMT}$ with uniform size. The TEM images depicted in Fig. $3 \mathrm{e}$ and $\mathrm{f}$ also confirm the uniform microplatelike morphology of $\mathrm{Cu}-\mathrm{HMT}$. Furthermore, the high resolution TEM image reveals the presence of a zig-zag-like metal ion chain structure ${ }^{46}$ and the SADF pattern reveals the existence of the metal nodes $\left(\mathrm{Cu}^{2+}\right)$. In addition, the energy-dispersion X-ray (EDX) spectra and elemental mapping also confirmed that the elements $\mathrm{C}, \mathrm{N}$, and $\mathrm{Cu}$ were present in $\mathrm{Cu}-\mathrm{HMT}$, as shown in

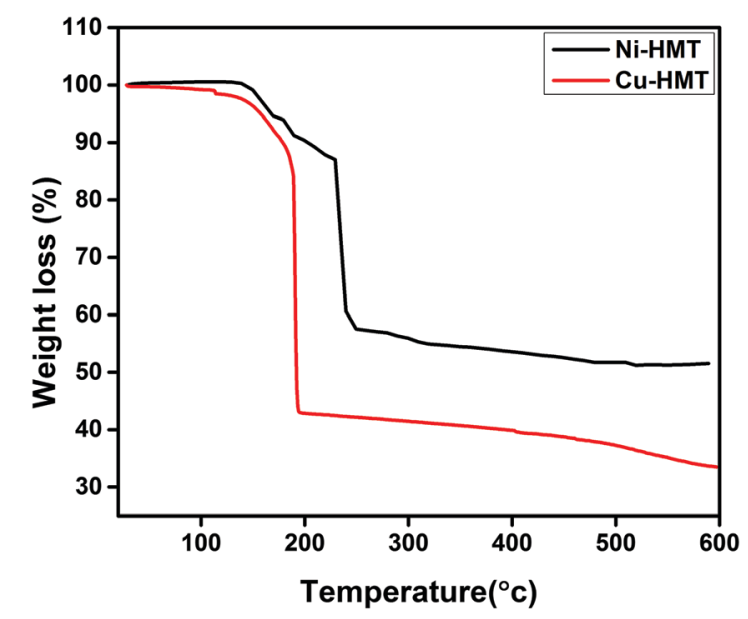

Fig. 4 TGA curves of the as-obtained $\mathrm{Cu}-\mathrm{HMT}$ and Ni-HMT. 

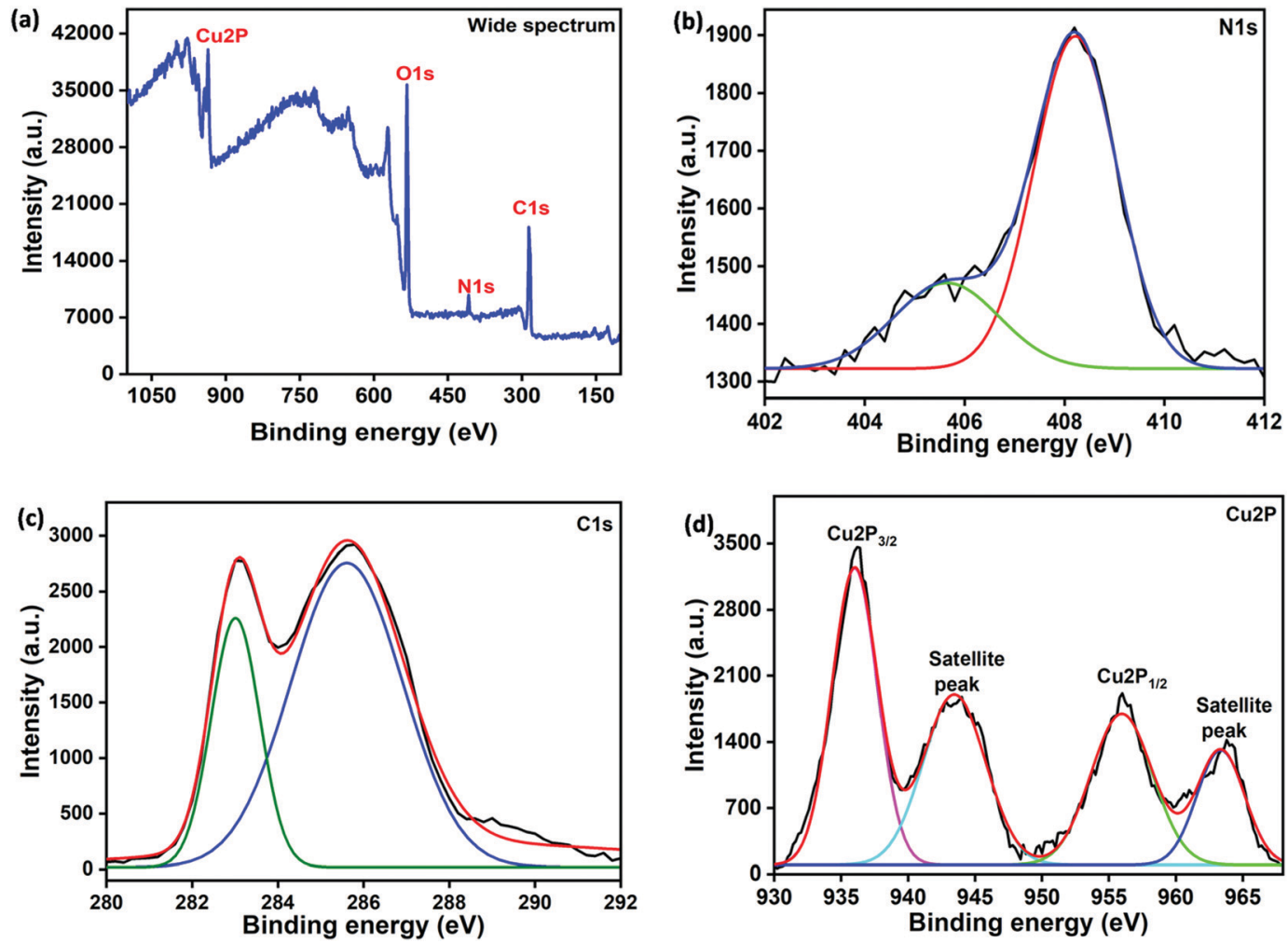

Fig. 5 XPS spectra of Cu-HMT: (a) survey, (b) N 1s, (c) C 1s, and (d) Cu 2p

Fig. $3 \mathrm{~g}$ and $\mathrm{h}$. Moreover, Ni-HMT was also confirmed using SEM, EDX and mapping, and the results are displayed in Fig. S1 and S2 (ESI + ). Based on the obtained microscopic results, we concluded that the $\mathrm{Cu}-\mathrm{HMT}$ and Ni-HMT had a microplate-like morphology.

To clarify the thermal stability of the obtained $\mathrm{Cu}-$ and $\mathrm{Ni}-$ HMT, they were evaluated using thermo-gravimetric analysis (TGA) over the temperature range $0-600{ }^{\circ} \mathrm{C}$, and the results are displayed in Fig. 4. The synthesized $\mathrm{Cu}$ - and Ni-HMT have good thermal stability up to 200 and $300{ }^{\circ} \mathrm{C}$, respectively; above these temperatures, they began to decompose. Cu-HMT has lower stability compared to Ni-HMT because of hydrogenation. However, $\mathrm{Cu}-\mathrm{HMT}$ has excellent water stability compared to $\mathrm{Ni}-\mathrm{HMT}^{47}$

The $\mathrm{N}_{2}$ adsorption-desorption studies determined the surface area of Ni-HMT and $\mathrm{Cu}-\mathrm{HMT}$, and the results are shown in Fig. S3 (ESI $\dagger$ ). As shown in Fig. S3 (ESI $\dagger$ ), the BrunauerEmmett-Teller (BET) surface area and pore volume of pristine $\mathrm{Ni}-\mathrm{HMT}$ and $\mathrm{Cu}-\mathrm{HMT}$ were found to be $212.186 \mathrm{~m}^{2} \mathrm{~g}^{-1}$ and $521.560 \mathrm{~m}^{2} \mathrm{~g}^{-1}$, and $0.223 \mathrm{cc} \mathrm{g}^{-1}$ and $0.393 \mathrm{cc} \mathrm{g}^{-1}$, respectively.
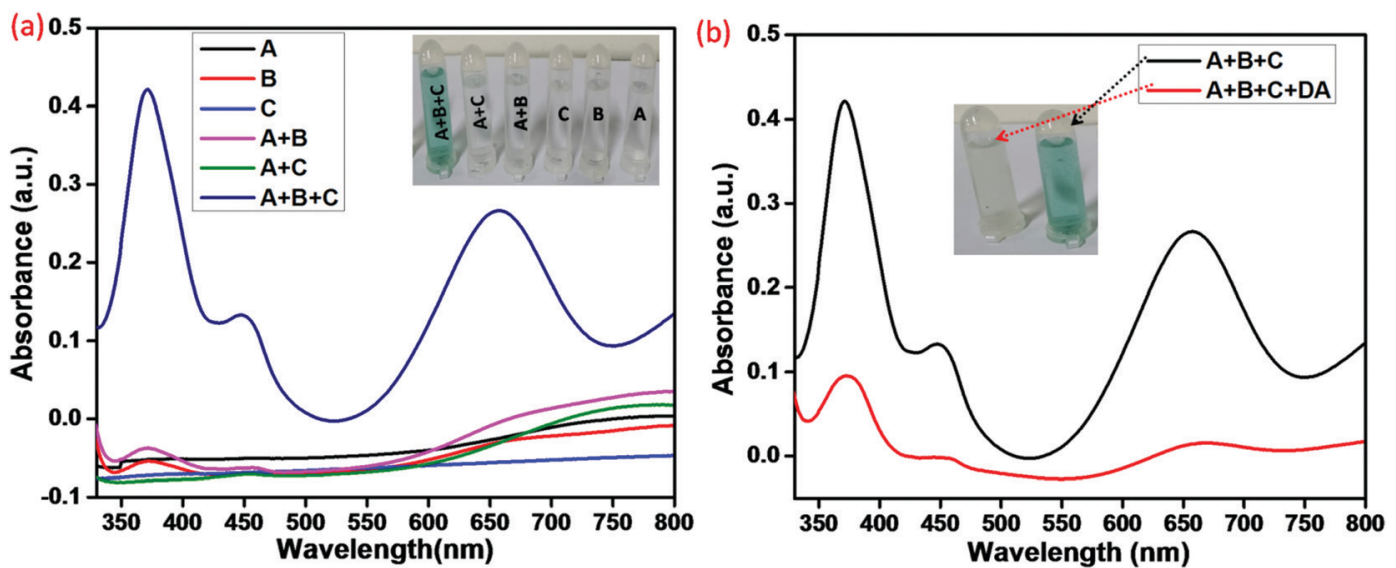

Fig. 6 (a) The UV-visible spectra of $\mathrm{Cu}-\mathrm{HMT}(\mathrm{A}), \mathrm{TMB}(\mathrm{B}), \mathrm{H}_{2} \mathrm{O}_{2}$ (C), $\mathrm{Cu}-\mathrm{HMT}+\mathrm{TMB}(\mathrm{A}+\mathrm{B}), \mathrm{Cu}-\mathrm{HMT}+\mathrm{H}_{2} \mathrm{O}_{2}(\mathrm{~A}+\mathrm{C})$, and $\mathrm{Cu}-\mathrm{HMT}+\mathrm{TMB}+\mathrm{H} \mathrm{O}_{2}$ $(A+B+C)$ with the corresponding photograph in the inset. (b) Absorption spectra in the presence and absence of DA; the color change is shown in the inset photograph. 
In this observation, $\mathrm{Cu}-\mathrm{HMT}$ had higher surface area and pore volume compared to Ni-HMT. High surface area promotes high catalytic activity for the oxidation of TMB. XPS analysis further verified the chemical bonding and chemical composition of $\mathrm{Cu}-\mathrm{HMT}$, as shown in Fig. 5. The wide-range spectrum of $\mathrm{Cu}-$ HMT confirmed the presence of $\mathrm{C}, \mathrm{N}$ and $\mathrm{Cu}$ (Fig. 5a). The highresolution $\mathrm{Cu} 2 \mathrm{p}$ spectrum showed two major characteristic peaks at 936.06 and $956 \mathrm{eV}$, which indicated the $\mathrm{Cu}^{2+}$ state in $\mathrm{Cu}-\mathrm{HMT}$, which suggested that $\mathrm{Cu}^{2+}$ could coordinate with the bidentate ligand. Moreover, associated satellite peaks were observed at binding energies of 943.46 and $963.26 \mathrm{eV}$, as shown in Fig. 5 d. ${ }^{48}$ As depicted in Fig. 5 b, the $\mathrm{N}$ 1s core-level spectrum of $\mathrm{Cu}-\mathrm{HMT}$ can be deconvoluted into peaks with binding energies of 405.72 and $408.23 \mathrm{eV}$, which were attributed to pyrrolic nitrogen $(\mathrm{C}-\mathrm{N}-\mathrm{C})$ and quaternary nitrogen, respectively. The C1s core-level spectrum exhibited peaks with binding energies of 282 and $285.6 \mathrm{eV}$, which were associated with $\mathrm{C}-\mathrm{N}$ and $\mathrm{sp}^{3}$ carbons (Fig. 5c). ${ }^{49}$ Based on the results, we concluded that the oxidation state $\mathrm{Cu}^{2+}$ existed in $\mathrm{Cu}-\mathrm{HMT}$ and that the nitrogen atom of HMT bound with $\mathrm{Cu}^{2+}$.

\subsection{Peroxidase-like activity of $\mathrm{Cu}-\mathrm{HMT}$}

In the visual detection method, the peroxidase-like activity is indispensable. On this basis, the method was intended to evaluate the peroxidase-like activity of $\mathrm{Cu}-\mathrm{HMT}$ via the oxidation of TMB. We analyzed the catalytic oxidation capacity of
$\mathrm{Cu}-\mathrm{HMT}$ using the results shown in Fig. 6, in which $\mathrm{Cu}-\mathrm{HMT}$ (A), TMB (B), and $\mathrm{H}_{2} \mathrm{O}_{2}$ (C) are clearly denoted. As shown in Fig. 6a, we did not observe any significant colour change in the systems including $\mathrm{A}, \mathrm{B}, \mathrm{C}, \mathrm{A}+\mathrm{B}$, or $\mathrm{A}+\mathrm{C}$. However, the combination $\mathrm{A}+\mathrm{B}+\mathrm{C}$ system revealed a robust colour change due to the oxidation of TMB (shown in the inset optical photograph). The colour shift clearly indicated that the asobtained $\mathrm{Cu}-\mathrm{HMT}$ has robust peroxidase-like catalytic function. Additionally, the UV-visible spectrum also a solid support for oxidation of the TMB with a absorbance band. In particular, the $\mathrm{A}+\mathrm{B}+\mathrm{C}$ system has viable peroxidase-mimic catalytic behavior due to the charge transfer process. Moreover, the prevention of the peroxidase-mimic activity was studied in the presence of DA. As shown in Fig. $6 \mathrm{~b}$, the A + B + C system exhibited a strong blue color due to oxidized TMB, as well as an absorption band at $A_{652} \mathrm{~nm}$. Interestingly, with the addition of DA to the blue-colored oxTMB, as predicted, the blue colour vanished, which suggested that DA inhibited the oxidation process. Additionally, an optical photograph clearly displayed a colour change in presence and absence of DA (shown in the inset photograph).

\subsection{Michaelis-Menten study}

The catalytic behavior of TMB and $\mathrm{H}_{2} \mathrm{O}_{2}$ was studied using the steady-state kinetic mode. The Michaelis-Menten curves were obtained by altering the concentration of either TMB or $\mathrm{H}_{2} \mathrm{O}_{2}$ as
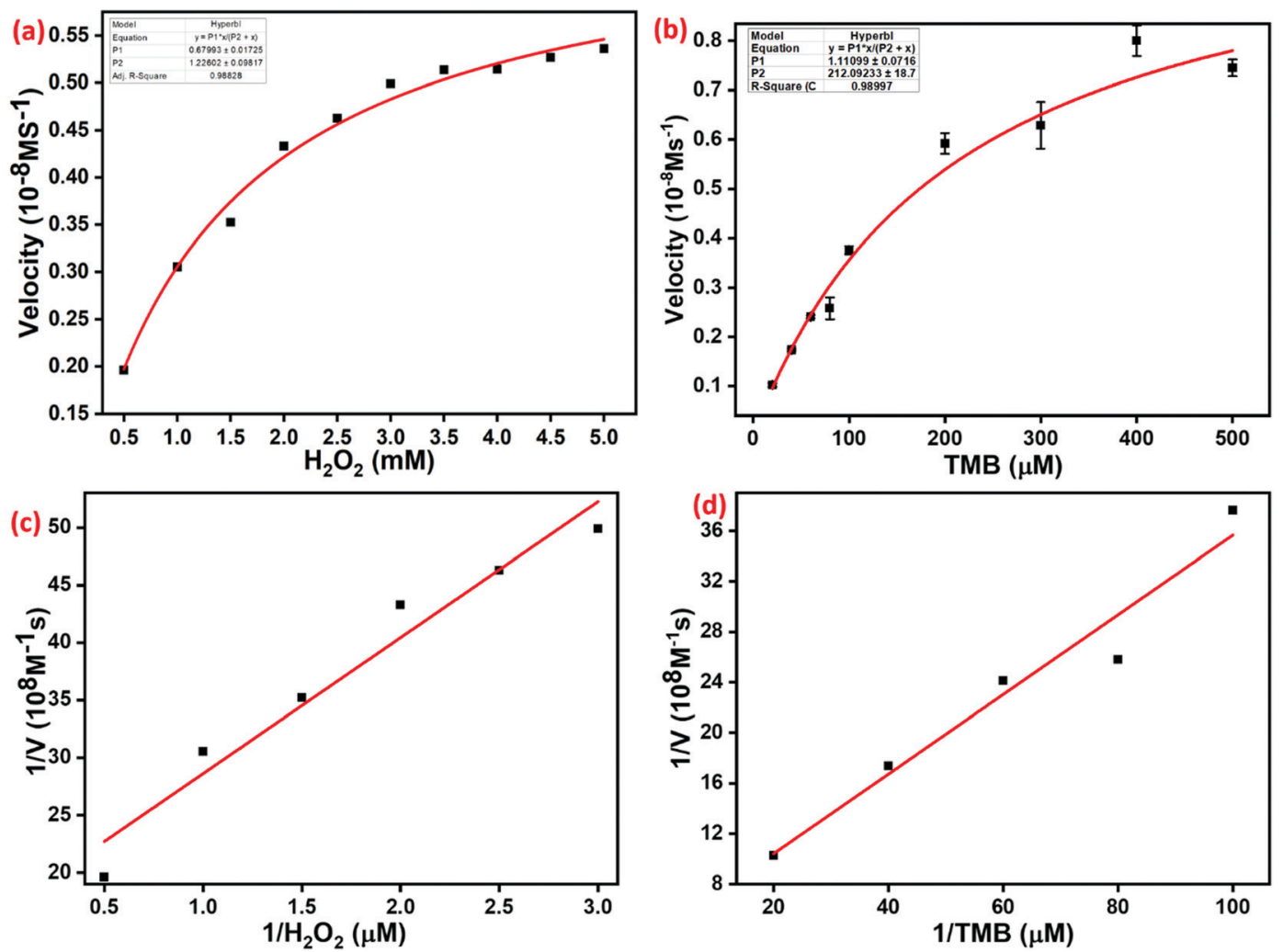

Fig. 7 (a) Kinetic data obtained by varying the $\mathrm{H}_{2} \mathrm{O}_{2}$ concentration while keeping the concentration of TMB constant. (b) Kinetic data obtained by varying the TMB concentration while keeping the concentration of $\mathrm{H}_{2} \mathrm{O}_{2}$ constant. ( $c$ and d) Lineweaver-Burk plots of the double reciprocal of the MichaelisMenten equations for $\mathrm{H}_{2} \mathrm{O}_{2}$ and TMB. 
Table 1 Comparison of the binding affinity and velocity for the peroxidase-like activity of HRP and other MOFs

\begin{tabular}{lllll}
\hline $\begin{array}{l}\text { Enzyme } \\
\text { mimic }\end{array}$ & Substrate & $\begin{array}{l}K_{\mathrm{m}} \\
(\mathrm{mM})\end{array}$ & $\begin{array}{l}V_{\max } \\
\left(10^{-1} \mathrm{M} \mathrm{s}^{-1}\right)\end{array}$ & Ref. \\
\hline HRP & $\mathrm{H}_{2} \mathrm{O}_{2}$ & 3.7 & 8.1 & 33 \\
& $\mathrm{TMB}$ & 0.434 & 10 & \\
MOF-808 & $\mathrm{H}_{2} \mathrm{O}_{2}$ & 1.06 & 1.39 & 50 \\
& $\mathrm{TMB}^{\mathrm{Cu}-\mathrm{HMT}}$ & 0.0796 & 3.12 & \\
& $\mathrm{H}_{2} \mathrm{O}_{2}$ & 0.68 & 1.343 & This \\
& $\mathrm{TMB}$ & 1.2 & 214 & work \\
\hline
\end{tabular}

the substrates. Moreover, the Michaelis-Menten curves (Fig. 7a and b) and Lineweaver-Burk plots (Fig. $7 \mathrm{c}$ and d) were obtained for TMB and $\mathrm{H}_{2} \mathrm{O}_{2}$ over a certain concentration range. Subsequently, we fitted the Lineweaver-Burk plot to calculate the Michaelis-Menten constant $\left(K_{\mathrm{m}}\right)$ and maximal initial velocity $(V)$ of the catalytic reaction involving Cu-HMT. The MichaelisMenten kinetics equation is $V=\left(V_{\max } \times[\mathrm{S}]\right) /\left(K_{\mathrm{m}}+[\mathrm{S}]\right)$. The Lineweaver-Burk double reciprocal plot is expressed as: $1 / V=\left(V_{\max } / K_{\mathrm{m}}\right)(1 /[\mathrm{S}])+\left(V_{\max } / 1\right) \cdot K_{\mathrm{m}}$ is the Michaelis-Menten constant, $V_{\max }$ is the maximum velocity, and $S$ is the substrate concentration. The value $K_{\mathrm{m}}$ is an important factor to determine the catalytic activity and the affinity between the enzyme and substrate. The $K_{\mathrm{m}}$ values of $\mathrm{Cu}-\mathrm{HMT}$ for the substrates $\mathrm{H}_{2} \mathrm{O}_{2}$ and TMB were $0.6799 \mathrm{mM}$ and $1.1343 \mathrm{mM}$. Moreover, the calculated $V_{\max }$ values of these two systems were $1.2 \times 10^{8} \mathrm{M}^{-1} \mathrm{~s}$ and $214.8 \times 10^{8} \mathrm{M}^{-1} \mathrm{~s}$, respectively. Moreover, the $K_{\mathrm{m}}$ value and $V_{\max }$ values of $\mathrm{Cu}-\mathrm{HMT}$ were compared with those of horseradish peroxidase (HRP) and other MOFs in Table 1. Based on the results, we concluded that as-prepared $\mathrm{Cu}-\mathrm{HMT}$ has superior binding affinity towards $\mathrm{H}_{2} \mathrm{O}_{2}$ and TMB, which enhanced the peroxidase-like activity.

\subsection{Peroxidase-like catalytic activity pathway}

The catalytic mechanism of $\mathrm{Cu}-\mathrm{HMT}$ was examined through trapping reactive oxygen species (ROS) during the catalytic reaction, and a comparison with related nanozymes and the resultant spectra are shown in Fig. 8. To clarify, the peroxidase-mimic reaction was carried out via ROS including hydroxyl $\left(\bullet^{\circ} \mathrm{OH}\right)$ and superoxide $\left({ }^{\circ} \mathrm{O}^{2-}\right)$, which are trapped by the radical scavengers IPA or methanol and $p$-benzoquinone (PBQ), respectively. As shown in Fig. 8a and Fig. S6 (ESI $\dagger$ ), Cu-HMT showed higher catalytic activity without any scavengers. The addition of IPA or methanol into the solution slightly reduced the $A_{652 \mathrm{~nm}}$ peak, indicating that a negligible quantity of hydroxyl radicals was produced, which suggests that the hydroxyl radical does not make a major contribution to the particular chromogenic oxidations. Furthermore, the absorption peak $A_{652 \mathrm{~nm}}$ was suppressed when PBQ was added to the initial solution, indicating the inhibition of peroxidase-like activity, which in turn indicates that the peroxidase-like activity is carried out specifically by ${ }^{\bullet} \mathrm{O}_{2}^{-}$. We then conducted an analysis using a nitroblue tetrazolium (NBT) superoxide dismutase (SOD) assay. NBT is commonly used for SOD analysis, and exhibits an absorbance band at $550 \mathrm{~nm}$ in the presence of riboflavin and light. ${ }^{56}$ In the same way, in our case, the absorption band of NBT at $550 \mathrm{~nm}$ in the presence of $\mathrm{Cu}-$ HMT and $\mathrm{H}_{2} \mathrm{O}_{2}$ was examined. The bare NBT had an absorption band with low intensity; after incubation with $\mathrm{Cu}-\mathrm{HMT}$ and $\mathrm{H}_{2} \mathrm{O}_{2}$, the NBT absorbance band at $550 \mathrm{~nm}$ increased due to the production of superoxide ions (Fig. S5, ESI $\dagger$ ). Further radical scavenger experiments also revealed ${ }^{\circ} \mathrm{O}_{2}{ }^{-}$to be a major reactive species in the $\mathrm{Cu}-\mathrm{HMT}$ system. The peroxidase mimic activity of Cu-HMT was compared with those of CuO NPs, NiO NPs, and Ni-HMT, and the results are displayed in Fig. 8b and Fig. S7 (ESI $\dagger$ ). Among them, Cu-HMT showed superior catalytic activity due to a higher concentration of ROS. Moreover, TMB and $\mathrm{H}_{2} \mathrm{O}_{2}$ can easily absorb on the surface of $\mathrm{Cu}-\mathrm{HMT}$. Therefore, the numerous lone-pair electrons will increase the electron density and mobility on the lattice of $\mathrm{Cu}-\mathrm{HMT}$, which decomposed $\mathrm{H}_{2} \mathrm{O}_{2}$ into reactive oxygen species $\left({ }^{\circ} \mathrm{O}_{2}{ }^{-}\right)$. Copper $\left(\mathrm{Cu}^{2+}\right)$ has redox properties that have been utilized for superoxide generation; copper $\left(\mathrm{Cu}^{+}\right)$directly activates molecular oxygen to superoxide $\left({ }^{\circ} \mathrm{O}_{2}{ }^{-}\right)$, but $\mathrm{Ni}^{2+}$ does not have the same properties. Indirectly, adsorption of the oxTMB substrate on HMT blocks the catalytic $\mathrm{Ni}^{2+}$ sites, similar to the results
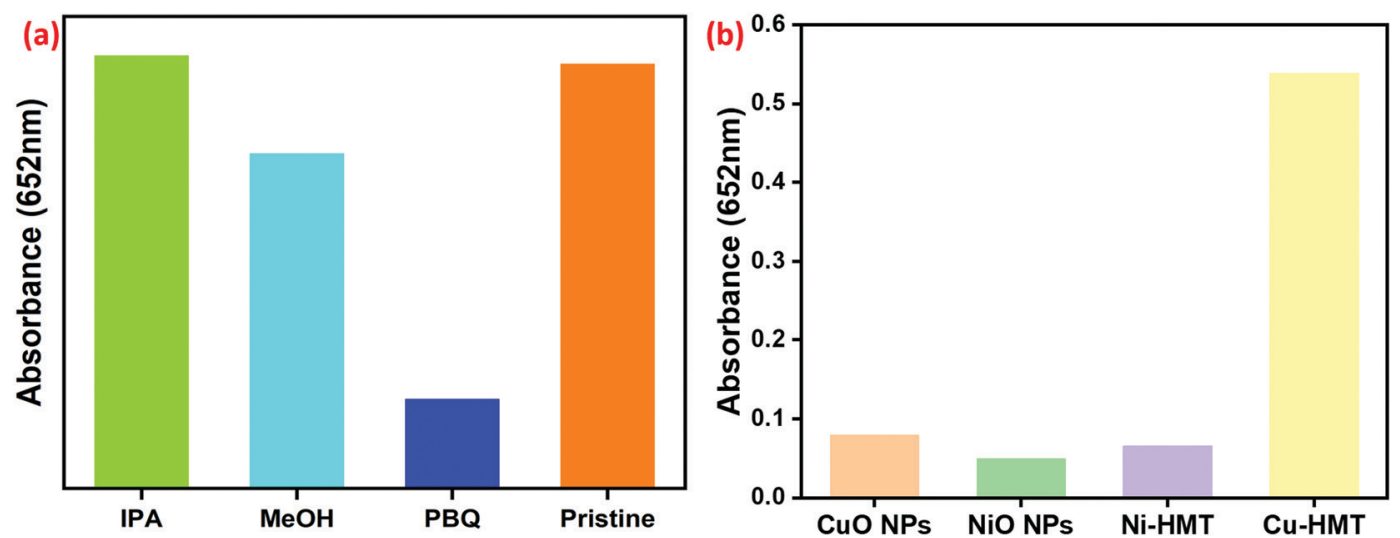

Fig. 8 (a and b) Absorption spectra results from the radical scavenging experiments and a comparison of the peroxidase-mimic activity of CuO NPs, $\mathrm{NiO}, \mathrm{Ni}-\mathrm{HMT}$ and $\mathrm{Cu}-\mathrm{HMT}$. 
Table 2 Comparison between the performances of various nanomaterials reported as DA sensors

\begin{tabular}{llllll}
\hline $\begin{array}{l}\text { Serial } \\
\text { no. }\end{array}$ & Material & Method & Linear range & $\begin{array}{l}\text { LOD } \\
(\mu \mathrm{M})\end{array}$ & Ref. \\
\hline 1 & Ag NPs & Colorimetric & $3.2-20 \mu \mathrm{M}$ & 1.20 & 51 \\
2 & Au NPs & Colorimetric & $2.5-20 \mu \mathrm{M}$ & 2.50 & 52 \\
3 & Cu $^{2+}$ & Colorimetric & $1-50 \mu \mathrm{M}$ & 1 & 53 \\
4 & CuS/rGO & Colorimetric & $2-100 \mu \mathrm{M}$ & 0.48 & 54 \\
5 & Cu-MOXs & Colorimetric & $0.5-20 \mu \mathrm{M}$ & 8.6 & 55 \\
6 & Cu(PDA)(DMF) & Colorimetric & $1-10 \mathrm{mM}$ & - & 26 \\
7 & Cu-HMT & Colorimetric & $0.5-3.5 \mathrm{mM}$ & 4.2 & This \\
& & & & & work
\end{tabular}

observed in the previous result. Ni-HMT has less activity compared to the Cu-HMT. The detection limits are also compared with those of other related nanozymes in Table 2.

\subsection{Optimization of the sensing conditions}

In the context of developing a Cu-HMT sensor with strong peroxidase activity, several experimental factors were optimized, including the amount of $\mathrm{Cu}-\mathrm{HMT}$, concentration of $\mathrm{TMB}$, concentration of $\mathrm{Cu}-\mathrm{HMT}$, time, temperature, and $\mathrm{pH}$ (Fig. 9). Prior to testing the sensor, the mimic catalytic activity was explored using various amounts of the prepared $\mathrm{Cu}-\mathrm{HMT}$ $(2,4,6,8$, and $10 \mathrm{mg})$, as shown in Fig. S4 (ESI $\dagger)$. Among them,
$6 \mathrm{mg}$ of $\mathrm{Cu}-\mathrm{HMT}$ exhibited higher catalytic activity compared to the other nanomaterial amounts. Consequently, the timedependent peroxidase-like activity was determined using $6 \mathrm{mg}$ of $\mathrm{Cu}-\mathrm{HMT}$ in $2 \mathrm{ml}$ buffer solution, and the results are displayed in Fig. 9a. Subsequently, as the concentration of $\mathrm{Cu}-\mathrm{HMT}$ was varied from 10-70 $\mu \mathrm{M}$ with $6 \mathrm{mg}$ of $\mathrm{Cu}-\mathrm{HMT}$ in the system, the absorption peak $A_{656 \mathrm{~nm}}$ gradually increased with a hypochromic effect; further increasing the concentration of $\mathrm{Cu}-\mathrm{HMT}$ did not result in any obvious absorption peak shift. These results are displayed in Fig. 9b. Among the tested concentrations, $70 \mu \mathrm{M}$ resulted in tremendous peroxidase-like activity. Moreover, we performed the reaction of $\mathrm{H}_{2} \mathrm{O}_{2}$, TMB and $\mathrm{Cu}-\mathrm{HMT}$ at different $\mathrm{pH}$ values (2 to 7 ), which resulted in colour change as well as absorption peak shift, as displayed in Fig. 9c. Among the tested $\mathrm{pH}$ values, those in the acidic range (pH 2 to 4) showed a yellowish color with an absorption band at $A_{420 \mathrm{~nm}}$, which corresponds to a two-electron transfer process. Furthermore, when the $\mathrm{pH}$ was increased to 4.5 and 5, the TMB changed from colorless to a blue color with an absorption peak at $A_{652 \mathrm{~nm}}$, demonstrating one-electron transfer. Interestingly, less peroxidase-like activity was observed above pH 5 to 7 due to the lower stability of $\mathrm{H}_{2} \mathrm{O}_{2}$ and TMB. The absorption spectra results reveal that $\mathrm{pH} 4.5$ resulted in superior peroxidase-like activity compared to the other $\mathrm{pH}$ values. Subsequently, the
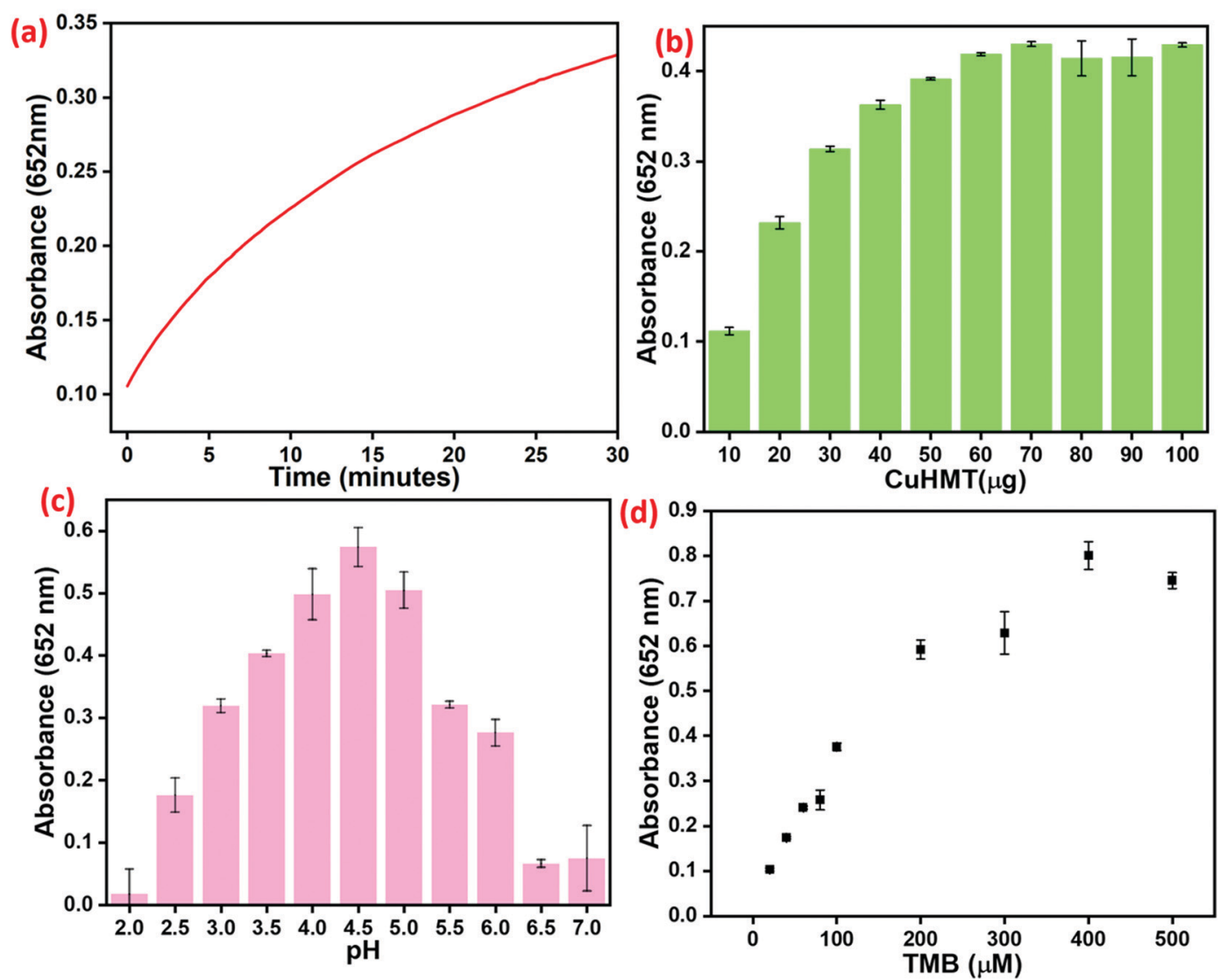

Fig. 9 Optimization experiments: absorbance at different times (a), using various concentrations of $\mathrm{Cu}-\mathrm{HMT}$ (6 mg) (b), different pH values (c) and different concentrations of the chromogenic substrate TMB (d). 

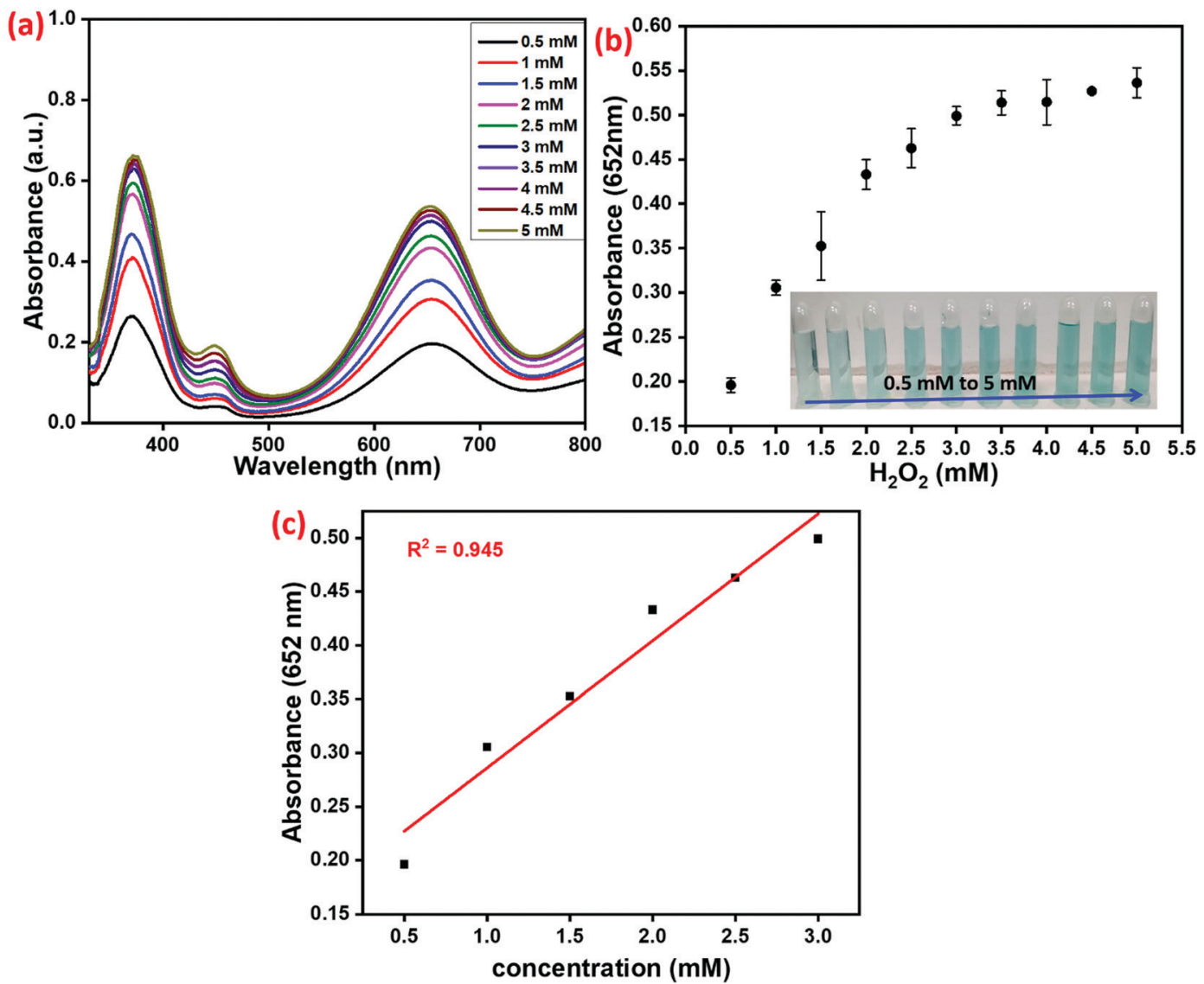

Fig. 10 (a) UV-vis spectra of the oxidized TMB product produced in the presence of different concentrations of $\mathrm{H}_{2} \mathrm{O}_{2}$. (b) Plot of the enhancement of the relative intensity of the absorbance band at $652 \mathrm{~nm}$ versus various concentrations of $\mathrm{H}_{2} \mathrm{O}_{2}$ (inset optical image shows the reaction system with different concentrations of $\mathrm{H}_{2} \mathrm{O}_{2}$ ). (c) Linear calibration plot for different concentrations of $\mathrm{H}_{2} \mathrm{O}_{2}$ in the reaction system.

concentration of TMB was optimized by varying the concentration of TMB, suggesting that the maximum activity occurred at $100 \mu \mathrm{M}$, as displayed in Fig. 9d.

The determination of $\mathrm{H}_{2} \mathrm{O}_{2}$ via peroxidase-mimic activity using the synthesized $\mathrm{Cu}-\mathrm{HMT}$ is shown in Fig. 10. The abovementioned optimized conditions for $\mathrm{Cu}-\mathrm{HMT}$ and TMB were used in the presence of various concentrations of $\mathrm{H}_{2} \mathrm{O}_{2}$, which decomposes the $\mathrm{H}_{2} \mathrm{O}_{2}$ into the reactive active species. Hence, the ROS produced from the different concentration of $\mathrm{H}_{2} \mathrm{O}_{2}$ could oxidize TMB, which turns blue in colour (Fig. 10a). Moreover, the absorption band was $A_{652 \mathrm{~nm}}$, which also indicates a one-electron transfer process. As shown in Fig. 10b, the enhancement of the relative intensity of the absorbance band at $A_{652} \mathrm{~nm}$ was plotted versus various concentrations of $\mathrm{H}_{2} \mathrm{O}_{2}$ (the inset photograph shows the reaction system with different concentrations of $\mathrm{H}_{2} \mathrm{O}_{2}$ ). A linear calibration plot $\left(R^{2}=0.945\right)$ was obtained for the different concentrations of $\mathrm{H}_{2} \mathrm{O}_{2}$ (Fig. 10c).

\subsection{Inhibition effect of DA}

After demonstrating the excellent peroxidase-like activity of the copper hexamine coordination framework (Cu-HMT), the inhibition effect on the peroxidase-like activity in the presence of DA was investigated. The strongly blue-colored oxTMB was associated with the absorption band at $652 \mathrm{~nm}$ in the abovementioned system in the absence of DA. However, the addition of DA into the system inhibited the peroxidase-like activity. The absorption spectra for different concentrations of DA ( $2.5 \mu \mathrm{M}$ to $20 \mu \mathrm{M}$ ) are shown in Fig. 11. As shown in Fig. 11a, the bright blue colour faded, and the absorption band at $A_{652 \mathrm{~nm}}$ was hypochromically shifted. The absorption peak attained a steady-state at $17 \mu \mathrm{M}$ of DA. Fig. $11 \mathrm{~b}$ shows the relative intensity of absorbance plotted versus various concentrations of DA. The inset digital photographic images display discoloration, which confirms the inhibition effect. The calibration curve of absorbance versus the concentration of DA was linear with a range of $2.5-17.5 \mu \mathrm{M}\left(R^{2}=0.946\right)$; the result is shown in Fig. 11c.

To analyze the selectivity of the prepared Cu-HMT, DA, UA, $\mathrm{AA}, \mathrm{Cy}, \mathrm{Fr}$ and $\mathrm{G}$ were selected as inhibitors of peroxidase-like activity. As shown in Fig. 12, the absorption intensity at $656 \mathrm{~nm}$ and the blue color of oxTMB remained unchanged before the addition of the inhibitors. Afterwards, we find that DA induces a surprising decrease in the absorption characteristics of the oxidized TMB relative to other interfacial substances; this finding indicates that the absorption peaks are modified in the presence of DA. Fig. $12 \mathrm{~b}$ and $\mathrm{c}$ present the relative identification efficiency of DA and the colour difference, which demonstrates that DA causes especially strong fading 
(a)

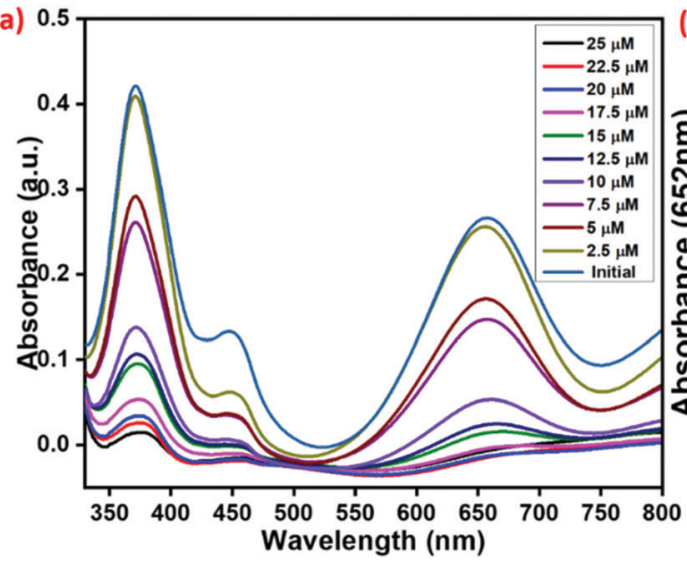

(c)
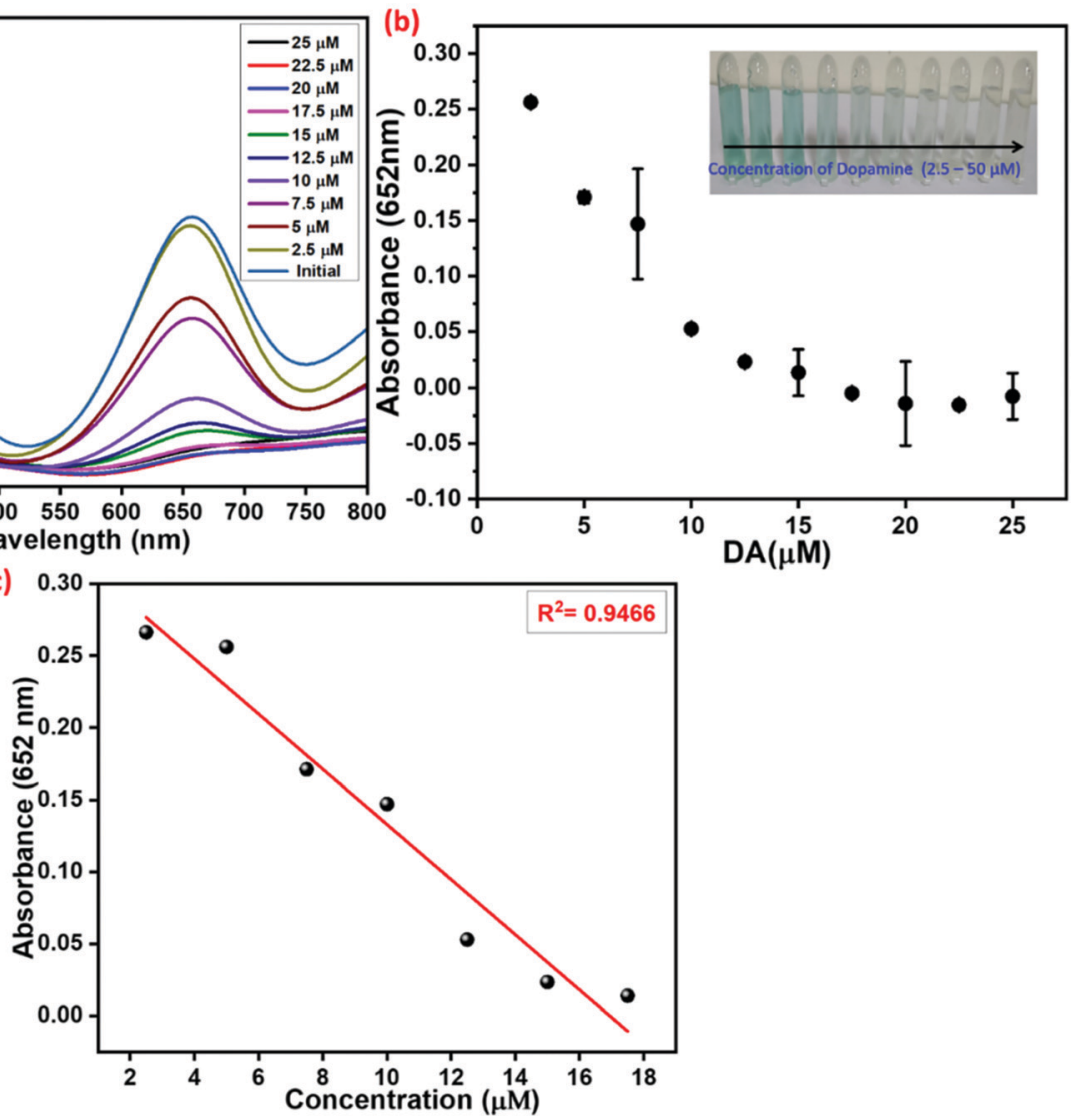

Fig. 11 UV-vis spectra of the oxidized TMB product in the presence of different concentrations of DA. (b) Plot of the suppression of the relative absorbance band intensity at $652 \mathrm{~nm}$ versus the concentration of DA (the inset optical image shows the reaction system with different concentrations of DA). (c) Linear calibration plot of different concentrations of DA in the reaction system.
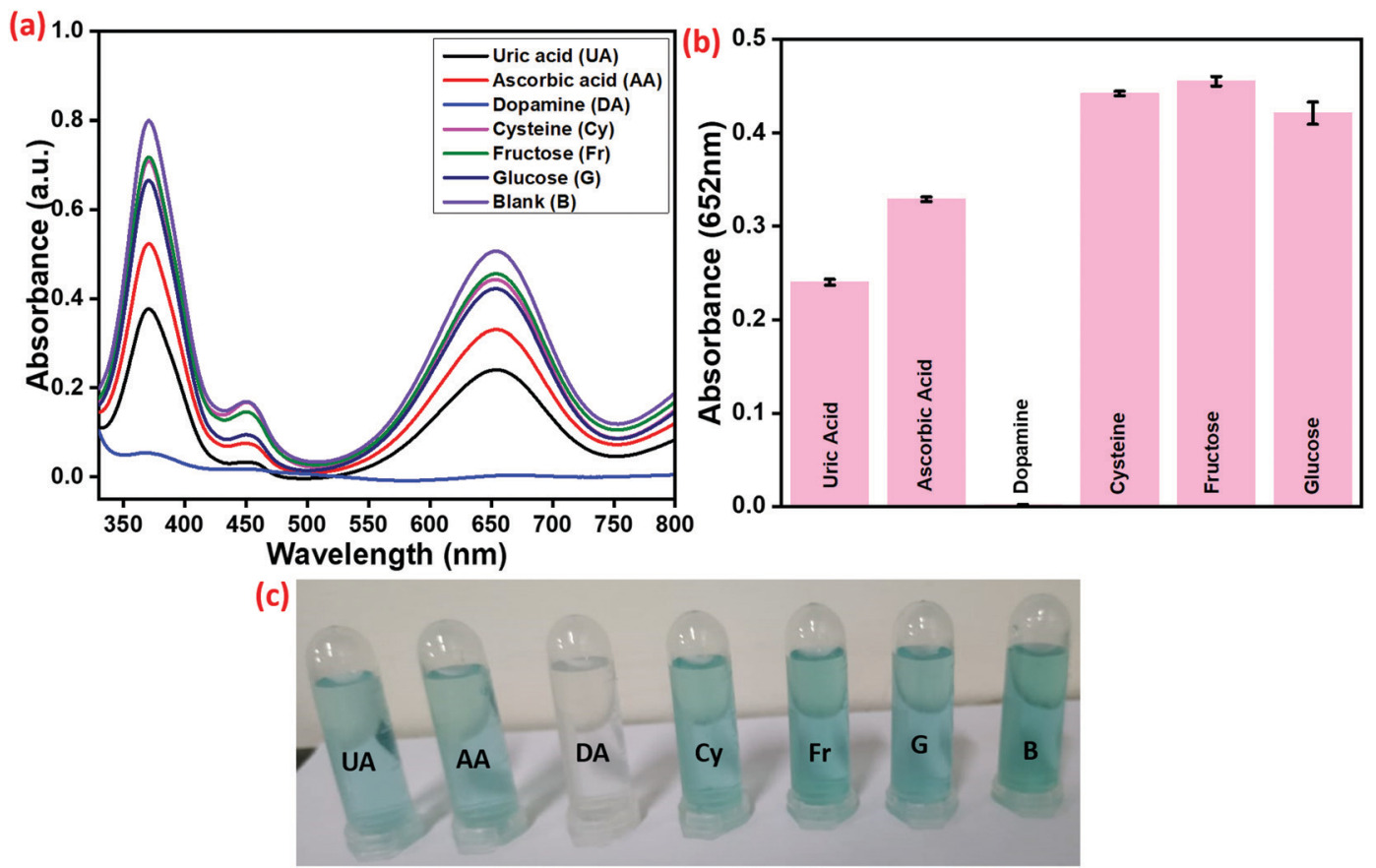

Fig. 12 (a) Selectivity of Cu-HMT towards DA detection in comparison to other interfering substances. (b) Bar plot of the relative detection efficiency showing the absorbance at $652 \mathrm{~nm}$. (c) Optical images of decolorization in the presence of DA. The standard values used for the selectivity study were: TMB $(100 \mu \mathrm{M}), \mathrm{H} 2 \mathrm{O} 2(100 \mu \mathrm{M})$, catalyst solution $\left(0.7 \mathrm{mg} \mathrm{mL}^{-1}\right)$ with DA $(50 \mu \mathrm{M})$ or other interferent substances $(100 \mu \mathrm{M})$. 
Table 3 Results for the determination of DA in human urine samples

\begin{tabular}{llll}
\hline Urine & DA spiked & DA found & Recovery (\%) \\
\hline 1 & 10 & 9.3 & 93 \\
2 & 20 & 17.5 & 92 \\
3 & 30 & 27.3 & 97
\end{tabular}

compared to the other substances. Finally, we infer that DA selectively blocks the peroxidase-like activity. Ascorbic acid shows a small extent of inhibition of the TMB oxidation. Further optimization of the preparation should be possible, and we will investigate this in the future. Additionally, real human samples were successfully analyzed with 93-97\% recovery, and the results are displayed in Table 3.

\section{Conclusion}

In summary, a facile one-pot method was developed to synthesize a transition metal $\left(\mathrm{Cu}^{2+}\right.$ and $\left.\mathrm{Ni}^{2+}\right)$-based coordination framework for the highly selective detection of $\mathrm{H}_{2} \mathrm{O}_{2}$ and DA. The prepared $\mathrm{Cu}^{2+}$ and $\mathrm{Ni}^{2+}-\mathrm{HMT}$ showed adequate peroxidaselike activity; $\mathrm{Cu}-\mathrm{HMT}$ has greater water stability as well as higher catalytic activity compared to Ni-HMT. Interestingly, $\mathrm{Cu}-\mathrm{HMT}$ displays remarkable enhancement and inhibition of its peroxidase-like activity towards $\mathrm{H}_{2} \mathrm{O}_{2}$ and DA detection compared to the other nanomaterials. Under the optimized conditions, the analytical performance of the developed colorimetric sensor exhibits excellent selectivity towards $\mathrm{H}_{2} \mathrm{O}_{2}$ and DA even in the presence of other molecules, with detection limits of $4.2 \mathrm{nM}$ and $0.7 \mathrm{nM}$, respectively. The proposed method is rapid, simple, reliable and highly feasible for real sample analysis, with the detection of DA being achieved in human urine samples. We believe that the as-synthesized $\mathrm{Cu}-\mathrm{HMT}$ with peroxidase-mimic activity is an ideal material for use in practical applications for versatile purposes.

\section{Conflicts of interest}

There are no conflicts to declare.

\section{Acknowledgements}

Authors acknowleges the "Selective Excellence Research Initiative Fund SRMIST-2021" from Department of Chemistry, SRM Institute of Science and Technology. This study was supported by the Department of Chemistry and SRM-SCIF from the SRM Institute of Science and Technology, Tamil Nadu - 603 203, India.

\section{References}

1 Y. Meng, W. Li, X. Pan and G. M. Gadd, Environ. Sci.: Nano, 2020, 7, 1305-1318.

2 J. Wu, X. Wang, Q. Wang, Z. Lou, S. Li, Y. Zhu, L. Qin and H. Wei, Chem. Soc. Rev., 2019, 48, 1004-1076.
3 H. Wei and E. Wang, Chem. Soc. Rev., 2013, 42, 6060-6093.

4 S. Cai and R. Yang, Nanozymology, Springer, 2020, pp. 331365.

5 L. Gao, J. Zhuang, L. Nie, J. Zhang, Y. Zhang, N. Gu, T. Wang, J. Feng, D. Yang and S. Perrett, Nat. Nanotechnol., 2007, 2, 577-583.

6 L. Huang, Q. Zhu, J. Zhu, L. Luo, S. Pu, W. Zhang, W. Zhu, J. Sun and J. Wang, Inorg. Chem., 2019, 58, 1638-1646.

7 S. He, L. Yang, P. Balasubramanian, S. Li, H. Peng, Y. Kuang, H. Deng and W. Chen, J. Mater. Chem. A, 2020, 8, 25226-25234.

8 S. R. Ahmed, J. Cirone and A. Chen, ACS Appl. Nano Mater., 2019, 2, 2076-2085.

9 Y. Liu, X. Wang and H. Wei, Analyst, 2020, 145, 4388-4397. 10 Y. Huang, J. Ren and X. Qu, Chem. Rev., 2019, 119, 4357-4412.

11 D. Wang, D. Jana and Y. Zhao, Acc. Chem. Res., 2020, 53, 1389-1400.

12 I. Nath, J. Chakraborty and F. Verpoort, Chem. Soc. Rev., 2016, 45, 4127-4170.

13 J.-R. Li, R. J. Kuppler and H.-C. Zhou, Chem. Soc. Rev., 2009, 38, 1477-1504.

14 M. Marieeswaran and P. Panneerselvam, RSC Adv., 2020, 10, 3705-3714.

15 J. Lee, O. K. Farha, J. Roberts, K. A. Scheidt, S. T. Nguyen and J. T. Hupp, Chem. Soc. Rev., 2009, 38, 1450-1459.

16 P. Karthik, R. Vinoth, P. Zhang, W. Choi, E. Balaraman and B. Neppolian, ACS Appl. Energy Mater., 2018, 1, 1913-1923.

17 S. Wang, W. Deng, L. Yang, Y. Tan, Q. Xie and S. Yao, ACS Appl. Mater. Interfaces, 2017, 9, 24440-24445.

18 L. Ai, L. Li, C. Zhang, J. Fu and J. Jiang, Chem. - Eur. J., 2013, 19, 15105-15108.

19 W. Dong, X. Liu, W. Shi and Y. Huang, RSC Adv., 2015, 5, 17451-17457.

20 Y. L. Liu, X. J. Zhao, X. X. Yang and Y. F. Li, Analyst, 2013, 138, 4526-4531.

21 D. Chen, B. Li, L. Jiang, D. Duan, Y. Li, J. Wang, J. He and Y. Zeng, RSC Adv., 2015, 5, 97910-97917.

22 H. Tan, Q. Li, Z. Zhou, C. Ma, Y. Song, F. Xu and L. Wang, Anal. Chim. Acta, 2015, 856, 90-95.

23 L. He, Z. W. Jiang, W. Li, C. M. Li, C. Z. Huang and Y. F. Li, ACS Appl. Mater. Interfaces, 2018, 10, 28868-28876.

24 S. Wang, W. Deng, L. Yang, Y. Tan, Q. Xie and S. Yao, ACS Appl. Mater. Interfaces, 2017, 9, 24440-24445.

25 H. Yang, R. Yang, P. Zhang, Y. Qin, T. Chen and F. Ye, Microchim. Acta, 2017, 184, 4629-4635.

26 F. Liu, J. He, M. Zeng, J. Hao, Q. Guo, Y. Song and L. Wang, J. Nanopart. Res., 2016, 18, 1-9.

27 Z. Ren, J. Luo and Y. Wan, ACS Appl. Mater. Interfaces, 2019, 11, 30542-30550.

28 M. K. Masud, J. Kim, M. M. Billah, K. Wood, M. J. Shiddiky, N. T. Nguyen, R. K. Parsapur, Y. V. Kaneti, A. A. Alshehri, Y. G. Alghamidi and K. A. Alzahrani, J. Mater. Chem. B, 2019, 7, 5412-5422.

29 R. Qin, Y. Feng, D. Ding, L. Chen, S. Li, H. Deng, S. Chen, Z. Han, W. Sun and H. Chen, ACS Appl. Bio Mater., 2021, 4(7), 5520-5528. 
30 S. Tanaka, M. K. Masud, Y. V. Kaneti, M. J. A. Shiddiky, A. Fatehmulla, A. M. Aldhafiri, W. A. Farooq, Y. Bando, M. S. A. Hossain and Y. Yamauchi, ChemNanoMat, 2019, 5, 506-513.

31 L. Jiao, W. Xu, Y. Zhang, Y. Wu, W. Gu, X. Ge, B. Chen, C. Zhu and S. Guo, Nano Today, 2020, 35, 100971.

32 S. Tanaka, Y. V. Kaneti, R. Bhattacharjee, M. N. Islam, R. Nakahata, N. Abdullah, S. I. Yusa, N. T. Nguyen, M. J. A. Shiddiky, Y. Yamauchi and M. S. A. Hossain, ACS Appl. Mater. Interfaces, 2018, 10, 1039-1049.

33 H.-Q. Zheng, C.-Y. Liu, X.-Y. Zeng, J. Chen, J. Lü, R.-G. Lin, R. Cao, Z.-J. Lin and J.-W. Su, Inorg. Chem., 2018, 57, 9096-9104.

34 P. Karthik, A. Pandikumar, M. Preeyanghaa, M. Kowsalya and B. Neppolian, Microchim. Acta, 2017, 184, 2265-2273.

35 M. Muppidathi, P. Perumal, R. Ayyanu and S. Subramanian, Analyst, 2019, 144(9), 3111-3118.

36 J. Segura-Aguilar, I. Paris, P. Muñoz, E. Ferrari, L. Zecca and F. A. Zucca, J. Neurochem., 2014, 129, 898-915.

37 P. Belujon and A. A. Grace, Int. J. Neuropsychopharmacol., 2017, 20, 1036-1046.

38 X. Wei, Z. Zhang and Z. Wang, Microchem. J., 2019, 145, 55-58.

39 H. Tang, P. Lin, H. L. Chan and F. Yan, Biosens. Bioelectron., 2011, 26, 4559-4563.

40 M. R. H. Nezhad, J. Tashkhourian, J. Khodaveisi and M. R. Khoshi, Anal. Methods, 2010, 2, 1263-1269.

41 D. Sun, S. Liu, G. Zhang and J. Zhou, Chem. Eng. J., 2019, 359, 1659-1667.
42 S. Liu, J. Zhou and H. Song, Small, 2018, 14, 1703548.

43 I. S. Ahuja, R. Singh and C. Yadava, J. Mol. Struct., 1980, 68, 333-339.

44 P. Afanasiev, S. Chouzier, T. Czeri, G. Pilet, C. Pichon, M. Roy and M. Vrinat, Inorg. Chem., 2008, 47, 2303-2311.

45 M. Kirillov, Coord. Chem. Rev., 2011, 255, 1603-1622.

46 S. Liu, J. Zhou and H. Song, Chem. Commun., 2018, 54, 9825-9828.

47 Y. Zhu, J. Ciston, B. Zheng, X. Miao, C. Czarnik, Y. Pan, R. Sougrat, Z. Lai, C.-E. Hsiung and K. Yao, Nat. Mater., 2017, 16, 532-536.

48 R. Sanz, F. Martínez, G. Orcajo, L. Wojtas and D. Briones, Dalton Trans., 2013, 42, 2392-2398.

49 P. Karthik, E. Balaraman and B. Neppolian, Catal. Sci. Technol., 2018, 8, 3286-3294.

50 D. Porter and H. Bright, J. Biol. Chem., 1983, 258, 9913-9924.

51 M. R. H. Nezhad, J. Tashkhourian, J. Khodaveisi and M. R. Khoshi, Anal. Methods, 2010, 2, 1263-1269.

52 R. Baron, M. Zayats and I. Willner, Anal. Chem., 2005, 77, 1566-1571.

53 H.-B. Wang, Y. Li, G.-L. Dong, T. Gan and Y.-M. Liu, New J. Chem., 2017, 41, 14364-14369.

54 S. Dutta, C. Ray, S. Mallick, S. Sarkar, R. Sahoo, Y. Negishi and T. Pal, J. Phys. Chem. C, 2015, 119, 23790-23800.

55 M. X. Guo and Y. F. Li, Spectrochim. Acta, Part A, 2019, 207, 236-241.

56 Y. Liu, Y. Zhang, Q. Liu, Q. Wang, A. Lin, J. Luo, Y. Du, Y. W. Lin and H. Wei, Analyst, 2021, 146, 1872-1879. 